\title{
Aspectos citológicos entre papanicolau e gravidez
}

\author{
Cytologic aspects between pap smear and pregnancy
}

Aspectos de la citología entre la prueba de papanicolaou y el embarazo

\section{Resumo}

A saúde feminina é um processo multifatorial e de muitas fases. Uma das mais importantes e frequentes problemáticas é o câncer de colo de útero, que deve ser rastreado em todos os períodos, inclusive na gravidez. Objetivo: no geral, temos: abordar a importância do exame de Papanicolau em mulheres grávidas. Já os específicos são: descrever os tipos celulares vistos nos exames de PCCU durante a gravidez, relacionando com a ação hormonal desta fase e relacionar os achados de microrganismos mais comuns nos resultados de PCCU em grávidas. Metodologia: revisão bibliográfica sistemática, com um total de 39 materiais selecionados, dentre artigos científicos, manuais ou sites institucionais em pesquisa de câncer - a maioria obtidos por bases de dados científicas e compreendendo os últimos 3 anos completos, em português e inglês. Resultados e Discussão: Foram abordados os fatores que contribuem para as taxas de adesão ao exame e também se percebeu a importância e segurança do procedimento, independente do período gestacional. Conclusão: O Papanicolau é confiável em gestantes, sua realização estando intimamente relacionada com níveis de educação sexual e de acesso a serviços de saúde, podendo melhorar significativamente a saúde feminina no país.

Palavras-chave: Teste de Papanicolaou; Gravidez; Doenças Sexualmente Transmissíveis; Neoplasias; Papillomaviridae.

\begin{abstract}
Women's health is a process full of factors and phases. One of the most important and frequent problems is cervix cancer, that should be tracked in all life periods, including pregnancy. Objectives: As general, we have: address the importance of the pap smear procedure in pregnant women. As for the specific ones, they are: describe the cellular types observed in pregnancy samples, correlating them to the hormonal action from the phase and connecting it to the most commonly found microorganisms in the results of expecting women. Methodology: Systematic literature review, with a total of 39 selected materials, including scientific papers, guideline manuals or websites from cancer research institutes - most of these obtained from scientific databases and considered within the last completed 3 years, in Portuguese and English. Results and Discussion: The factors that contribute to the rates of acceptance of the procedure were discussed, as well as the levels of importance and safety around pap smear, independently of gestation period. Conclusion: The pap smear is a trustworthy process for pregnant women, and having it done is directly related to the levels of sexual education and access of healthcare services, being then able to significantly increase the women's health around the country.
\end{abstract}

Keywords: Papanicolaou Test; Pregnancy; Sexually Transmitted Diseases; Neoplasms; Papillomaviridae.

\section{Resumen}

La salud femenina es un proceso multifactorial y con muchas fases. Uno de los problemas más importantes y frecuentes es el cáncer de cuello uterino, al que se debe realizar un rastreo en todo momento, incluso durante el embarazo. Objetivo: en general, tenemos: abordar la importancia de la prueba de Papanicolaou en mujeres embarazadas. Los específicos son: describir a los tipos de células que se observan en estos exámenes durante el embarazo, relacionar la acción hormonal de esta fase y lo que se es posible encontrar como siendo los microorganismos más comunes en los resultados de papanicolaou en mujeres embarazadas. Metodología: revisión bibliográfica sistemática, con un total de 39 materiales seleccionados, entre artículos científicos, manuales o sitios de 
web institucionales que hacen pesquisas en la investigación del cáncer, la mayor parte obtenida de bases de datos científicas y que comprenden los últimos 3 años completos, en portugués e inglés. Resultados y Discusión: Se abordaron los factores que contribuyen a los números de adherencia a la prueba y también se percibió la importancia y seguridad del procedimiento, independientemente del período gestacional. Conclusión: las pruebas de Papanicolaou son confiables en mujeres embarazadas y su desempeño está estrechamente relacionado con los niveles de educación sexual y acceso a los servicios de salud, algo que, si regalado definitiva atención puede mejorar significativamente la salud de las mujeres en el país.

Palabras clave: Prueba de Papanicolaou; Embarazo; Enfermedades de Transmisión Sexual; Neoplasias; Papillomaviridae.

\section{Introdução}

Estima-se, de acordo com o Instituto Nacional do Câncer [INCA], que no Brasil anualmente surgem mais de 16.000 casos de câncer do colo do útero, onde a maior parte das infecções evoluem para tumores pela persistência do HPV (papilomavírus humano), não excluindo os outros fatores como tabagismo; multiplicidade de parceiros sexuais e uso excessivo de anticoncepcionais. O exame de Papanicolau auxilia na detecção de lesões ocasionadas pelas alterações celulares decorrentes do vírus, e com isso auxilia a rapidez no início do tratamento (INCA, 2020).

A gravidez é uma fase na vida da mulher que gera inseguranças em relação ao desenvolvimento do embrião, alterações fisiológicas e imunológicas são afetadas bruscamente, deixando-a mais suscetível a infecções no geral. Mulheres jovens tendem a ter maiores índices de infecção por conta da coitarca, iniciada no período da adolescência - entre seus 14 a 18 anos - evento que se correlaciona com a exposição da zona de transformação, que está alta atividade mitótica e apresenta células imaturas e as alterações hormonais comuns da fase, fazendo com que quando a mulher venha a engravidar, o aumento de hormônios esteroides - especificamente progesterona - facilitem o ciclo de replicação do vírus - que tem como alvo células sincicitrofoblastas, células responsáveis pela liberação de enzimas para implantação do blastocisto no endométrio - as regiões longas de controle (Low Copy Regions - LCR) não codificadas do genoma viral tem por vez uma estrutura parecida com hormônios esteroides, possibilitando a reação de esteroide com receptores de glicocorticóides, permitindo o sequenciamento de LCR análogo. O LCR tem o papel de transcrição e replicação, gerando sinais que venham controlar outros genes virais (Sousa et al., 2018) (Bober, 2019).

A colposcopia é segura de ser realizada durante a gravidez devido a exteriorização da zona de transformação por conta da remodelação de superfície do colo uterino e aumento de vascularização. É comum os achados de atrofia e infiltrados inflamatórios, pontos que podem dificultar a leitura, e a abundância de muco devido a fase gestacional (Agarwal, 2019).

A maior dificuldade na realização do exame é a adesão das próprias gestantes, por uma maior parte ser jovem, tem a negativa a realização do mesmo, por falta de acesso ou informação muitas acabam nem sabendo que estavam infectadas, levando o risco de transmissão ao feto durante toda a gestação e pós parto. Mesmo que exista atualmente meios contraceptivos eficazes, a utilização incorreta dos mesmos gera a gravidez indesejada e a exposição a IST. Por ser um vírus de característica assintomática e latente, a disseminação se torna facilitada pela despreocupação dos jovens e adolescentes em relação ao uso de métodos contraceptivos. Fatores sociais possuem uma influência grande nesses casos, pois ao invés de buscarem informações em fontes seguras e confiáveis, se baseiam em exemplos e narrativas de conhecidos ou familiares, e não nas políticas estabelecidas como de saúde pública (Costa \& Ribeiro, 2019) (Cirino, 2020).

Em qualquer situação clínica, o principal objetivo é o de garantir a manutenção de um estado saudável e da qualidade de vida. Para assegurar uma assistência completa, deve-se levar em conta que saúde é um conceito amplo e primariamente definido como "um estado de completo bem-estar físico, mental e social e não somente ausência de afeções e enfermidades", pela Organização Mundial da Saúde [OMS] (1948). Sendo assim, qualquer condição que esteja atrelada a uma dificuldade em obedecer a este parâmetro, configura-se como um desbalanço nesta relação - e o potencial estabelecimento de uma doença. 
No caso dos desafios encontrados na saúde feminina, um dos principais é conectado com a associação entre o HPV e o câncer de colo de útero. Por mais que neoplasias sejam multifatoriais - e nessa em específico, alguns outros fatores de risco possam incluir: tabagismo, imunossupressão, múltiplos parceiros e início precoce de atividade sexual - a infecção viral neste caso é um importante fator de favorecimento. (Guimarães et al., 2020).

O Papiloma Vírus Humano (Human Papilloma Virus - HPV) é um vírus de DNA pertencente à família Papovaviridae e classificado de acordo com inúmeros subtipos, sendo estes decididos com base no nível de modificações celulares que podem induzir: os de baixo e alto risco. É importante salientar que todos podem desencadear crescimento celular, mas apenas os de alto risco podem apresentar potencial oncogênico (Costa \& Ribeiro, 2019)

De acordo com o Instituto Nacional do Câncer, o número de subtipos oncogênicos do HPV chega a pelo menos 13, sendo que dentre estes, os responsáveis por cerca de 70\% dos casos de câncer de colo de útero (CCU) são os subtipos 16 e 18 . (INCA, 2021).

O câncer de colo de útero é relevante para estudos por ser categorizado como uma questão de saúde pública, principalmente em função da sua alta capacidade de morbimortalidade - afetando em sua maioria mulheres de condições socioeconômicas mais desfavorecidas. Estatísticas mostram que é correspondente a 10\% dos casos de câncer para mulheres no mundo e estimam que pelo menos 500 mil sejam adicionados, anualmente (Silveira et al., 2018).

Nacionalmente, este tipo de câncer é o terceiro mais frequente na população feminina de modo geral, ficando atrás apenas do câncer de mama e do colorretal. A estimativa de novos casos de CCU entre os períodos de 2020 até 2022 gira em torno de 16.590 novos casos por ano. Deve-se ainda levar em consideração que a região norte possui as estatísticas maiores dentro do território do país, aonde se espera que os números de CCU sejam equivalentes ao câncer de mama, e que a cada 100 mil mulheres, pelo menos em torno de 21 mil apresentem a doença (INCA, 2020).

A infecção por HPV ou a neoplasia a ela relacionada podem acontecer em qualquer fase da vida da mulher - desde que ela esteja exposta aos fatores de risco - inclusive a gestacional. Especialmente em mulheres jovens, grávidas pela primeira vez, em relacionamentos instáveis e com pouco conhecimento acerca de sua prevenção ou tratamento (Sousa et al., 2018).

Quanto aos números de incidência nesse período, estudos conduzidos a nível nacional afirmam que em gestantes a neoplasia do colo de útero é considerada a mais comum de todas (Costa et al., 2018) e que seus níveis de prevalência giram em torno de $25.3 \%$ - números bem maiores quando comparados aos $13 \%$ de casos em mulheres não grávidas. Sendo assim, a associação entre gestação e maiores níveis de acometimento por HPV é legítima (Tanaka et al., 2019).

Algumas razões fisiológicas que explicam a maior incidência em grávidas podem ser: alteração do sistema imune, sob um espectro de imunodepressão, diferente comportamento hormonal, aumento da taxa de replicação viral, especialmente se houver uma infecção na segunda metade do período gestacional (Singhal et al., 2009 como citado em Cirino \& Barbosa, 2020).

Essa patologia é de fácil prevenção, podendo-se destacar como principais metodologias: a atenção a iniciativas de educação sexual, o uso de preservativos e a aplicação de vacinas dentro da faixa etária recomendada, além do cuidado necessário aos esquemas de realização do exame de Papanicolau (Rodrigues Rosa et al., 2018). Esse exame é considerado como o padrão ouro para o diagnóstico citológico (Ethirajan et al., 2018).

De modo geral, o diagnóstico do HPV pode ser feito por métodos clínicos, que observam as lesões e seus aspectos; e laboratoriais, podendo estes serem divididos em: técnicas de biologia molecular e de citologia. No caso da biologia molecular, a mais utilizada é a Reação em Cadeia da Polimerase (Polymerase Chain Reaction - PCR), que permite a identificação do material genético viral (Oliveira et al., 2019). No caso da citologia, a técnica indicada para um rastreamento e diagnóstico eficientes é a de Papanicolau, que permite a observação de lesões no epitélio do colo uterino (Priya \& Shankar, 2019).

As recomendações para a realização do Papanicolau, de acordo com a Biblioteca Virtual em Saúde, do Ministério da Saúde [BVSMS], são: deve ser realizado em todas as mulheres com idade entre 25 e 64 anos, inicialmente com periodicidade 
anual e após dois resultados negativos consecutivos, o intervalo aumenta para três anos entre exames (BVSMS, 2011). De acordo com dados fornecidos pelo INCA, o estabelecimento da faixa etária é justificado pois é o período de tempo aonde ocorrem a maior parte das lesões intraepiteliais de alto grau (High-Grade Squamous Intraepithelial Lesions - HSIL) - podendo assim, estas serem tratadas em tempo hábil para que não evoluam. (INCA, 2020).

De acordo com as diretrizes padrão estabelecidas pela OMS a incidência desta neoplasia começa a aumentar em mulheres de 30 até 39 anos, atingindo níveis máximos entre os 50 e 60 anos. Sendo assim, a realização correta e frequente dos exames de Papanicolau permite que, em idades mais jovens, as lesões de baixo grau (Low-Grade Squamous Intraepithelial Lesions - LSIL) sejam tratadas e revertidas antes de se tornarem um pior prognóstico. Da mesma maneira em uma paciente acima dos 60 que não tenha diagnosticado lesões, a probabilidade delas se desenvolverem após pausado o acompanhamento é mínima (OMS, 2002). Isso é geralmente explicado pela velocidade de evolução, que corresponde a décadas. Sendo assim, se uma paciente nessa faixa etária possui rastreamento regular e resultados normais, pode-se considerar a efetividade plena do exame (Ministério da Saúde, 2021).

Levando em conta também os aspectos sociais e de acesso à educação sexual, de maneira geral é preconizado que o exame deve ser realizado por toda e qualquer mulher que tenha vida sexual ativa, incluindo as gestantes - especialmente pelo momento oportuno, de pré-natal (Teixeira, et al., 2019).

No caso especifico das gestantes, é especialmente indicado que o exame seja solicitado logo na primeira consulta de acompanhamento, como uma estratégia para garantir que ele seja feito. Números mostram que a cobertura de mulheres grávidas em atendimentos de pré-natal corresponde a cerca de $90 \%$. Se todas elas fizessem o rastreamento citológico, o panorama de casos de CCU no território Brasileiro poderia ser extremamente diferente, apresentado considerável melhora (Terlan \& Cesar, 2018).

O exame funciona normalmente a partir da coleta dos epitélios da endocérvice e ectocérvice, que correspondem respectivamente, as regiões mais internas e externas do trato genital feminino (Ministério da Saúde, 2013).

Para a coleta da endocérvice, se utiliza a escova endocervical, aplicada com movimentos giratórios em $360^{\circ}$. E para obter material da ectocérvice, utiliza-se da espátula de Ayre, performando uma leve raspagem (Coleta de materiais citológicos, 2017).

No caso da coleta em gestantes, o Ministério da Saúde orienta que a coleta pode ser feita a qualquer momento da gravidez (Ministério da Saúde, 2021), porém obtendo apenas amostras provenientes apenas da ectocérvice - uma vez que, por ação hormonal da gestação, a junção escamo-colunar (JEC) se encontra exteriorizada, não sendo necessária à coleta endocervical propriamente dita (Rodrigues Rosa et al., 2018) (Guimarães et al., 2020). A diferença na localização da junção escamo colunar é o que explica a pequena mudança de grupos celulares a serem obtidos, estando representada abaixo, na Figura 1: 
Figura 1: Aspectos da JEC e estrutura do trato genital feminino.

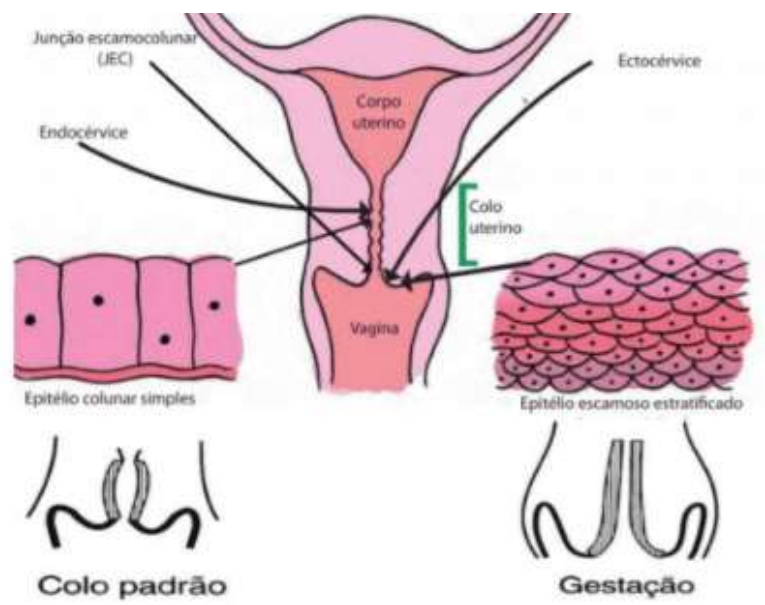

Fonte: Adaptada de Ritterbusch et al. 2018 e Citopatologia Ginecológica, 2012.

As gestantes apresentam algumas condições únicas, principalmente no que se relaciona com seus aspectos hormonais e celulares. Em relação aos seus hormônios, os mais atuantes são estrogênio, progesterona, gonadotrofina crônica humana (Human Chorionic Gonadotropin - HCG) e somatomamotropina coriônica humana (Human Chorionic Somatomammotropic Hormone - HCS). Os efeitos destes hormônios são diversos, mas se relacionam principalmente em: promover as mudanças corporais necessárias para a sustentação da gravidez, regular os componentes do trato genital feminino e nutrir o feto (Da Silva et al., 2018).

Dentro da leitura em citologia, é importante notar que ela é diretamente dependente e influenciada pela situação hormonal da mulher - podendo por ele ser alterada a nível de espessura (deixando o epitélio mais fino), maturidade (diminuição no número de células superficiais, passando a ser revestido majoritariamente por intermediárias e seguindo para parabasais e basais) e renovação do epitélio (maturação e replicação celular precisam de hormônios), comportamento de pH (meio mais acídico) e quantidades de glicogênio (produção aumentada e criação das células naviculares). Essas condições, em conjunto, favorecem que o período gestacional apresente um maior número de episódios inflamatórios, especialmente vaginoses, vaginites e infecções fúngicas - merecendo destaque, em cada, Lactobacillus spp., Gardnerella vaginalis e Candida spp. (Sousa et al., 2019).

A Figura 2 mostra alguns dos achados citológicos registrados pela Agência Internacional para Pesquisa de Câncer (International Agency for Research on Cancer - IARC) que se focam justamente nos mais frequentes, descritos no parágrafo anterior.

Figura 2: Estrutura do epitélio e microrganismos mais encontrados em citologia.

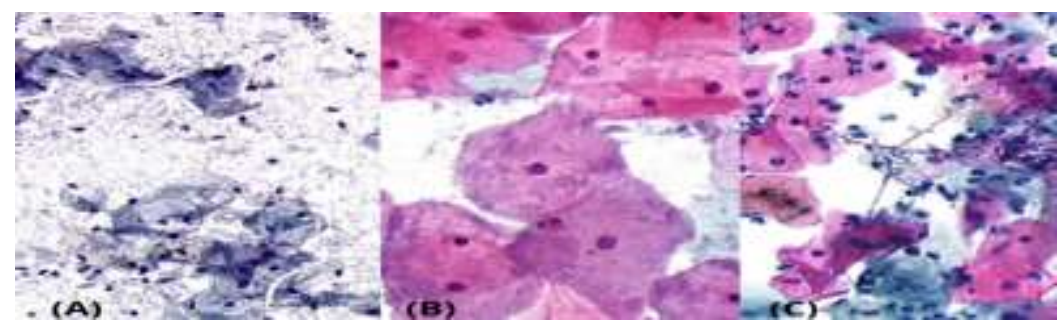

Fonte: Adaptada de IARC Atlas Digital (2021).

Na porção A temos uma mulher em fase luteínica, com bordas citoplasmáticas, abundância de lactobacilos e citólise com registro feito em objetiva de 100x. Já na faixa $\mathrm{B}$, temos a observação de um quadro de vaginose bacteriana, causa pela 
presença de Gardnerella vaginalis e que pode se apresentar com sintomas de desconforto, corrimento e prurido raro. Por último, na área C, é possível que se encontrem hifas e esporos de cândida, em fundo inflamatório.

Além dos fatores que dizem respeito ao período gestacional, a resistência ao exame Papanicolau também conta com fatores externos a este tempo em específico, sendo os principais: medo do diagnóstico gerado, baixa escolaridade, condições econômicas - tanto pessoais quanto em classificação do país - menos favorecidas, número considerável de parceiros sexuais e falha na aplicação de meios de prevenção - principalmente preservativos e vacinas (Leite et al., 2018).

Para casos aonde o rastreamento foi inexistente ou feito em períodos incorretos, as chances de se descobrir uma neoplasia quando a paciente for realizar o procedimento são maiores. No caso do período gestacional, entende-se como essa classificação, um câncer que acontece durante a gravidez ou até 12 meses após o parto. Seu tratamento precisa levar em consideração idade gestacional, estadiamento da doença, tipo de droga e sua dosagem - estando aqui descrito que quimioterapia pode ser feita apenas nos segundos e terceiros trimestres de gestação e a radioterapia é contraindicada sob qualquer aspecto (Lélis et al., 2019).

\section{Metodologia}

Para a realização do presente artigo foi conduzida uma revisão bibliográfica do tipo sistemática, uma vez que este tipo de apanhado é considerado como o de modalidade científica, já que além de explicar sobre um tópico, também possui caráter exploratório, o que permite análise crítica sobre o possível futuro da linha de pesquisa proposta.

São consideradas revisões de caráter qualitativo, uma vez que apenas observam algum aspecto relativo ao tema central, sem oferecer dados numéricos concretos (no caso da pesquisa, os dados apresentados foram as estimativas de casos de câncer, que mudam conforme os anos) - sendo também conhecidos como estudos observacionais e retrospectivos.

São revisões que partem de dados primários e científicos, buscando sempre trazer evidências que sejam relacionadas a um tema ou problema - sendo necessário que se desenvolva uma pergunta para responder, se selecionem bases de dados para obtenção de informações confiáveis, se usem filtros e critérios dentro destas bases e a condução do estudo seja estratégica, metodológica e crítica. O seu ponto principal é o de responder o questionamento derivado do tema com evidências científicas (Casarin et al., 2020).

Como ponto norteador deste artigo, buscou-se expor a importância do exame preventivo de câncer de colo de útero, sobretudo destacando a sua associação com o diagnóstico da doença, os seus aspectos citológicos, a importância da sua realização em todas as fases aonde a mulher é sexualmente ativa - prestando atenção especial e fornecendo informações adequadas sobre o período gestacional.

Para tanto, foram utilizados materiais de cunho científico publicados - principalmente artigos de pesquisa e manuais; no caso destes últimos, sendo desenvolvidos por órgãos governamentais, mundiais ou intimamente ligados a pesquisa de câncer - que foram encontrados através de bases de dados acadêmicas.

Como portais de artigos utilizados para artigos, destacam-se principalmente: Scientific Electronic Library Online (Scielo), Pubmed, Elsevier, Science Direct, Periódicos Capes, Biblioteca Virtual em Saúde (BVS), Literatura LatinoAmericana e do Caribe em Ciências da Saúde (Lilacs) e Google Acadêmico. Já para estatísticas e dados gerais mais relativos ao tópico de neoplasia, forma amplamente utilizados portais como: INCA, IARC, OMS, Ministério da Saúde e IBGE.

Como idiomas aceitos temos português e inglês - de modo a expandir a quantidade de material. Já como período de publicação, a maior parte é oriunda dos últimos 3 anos completos, correspondendo o espaço de tempo entre 2018 e 2021 - com exceção de tópicos onde foi necessário o uso de manuais desenvolvidos por órgãos governamentais ou de saúde (nesse caso, os apresentados na escrita do trabalho são sempre os mais recentes que podem ser encontrados nos arquivos disponíveis). 
De modo geral, os critérios de inclusão e exclusão contemplam estes pontos: a linha do tempo de publicação (limitada aos anos descritos), o par de idiomas e a conformidade com o tema proposto, sendo assim capazes de acrescentar informações sobre a técnica citológica associada com a condição gestacional da paciente.

Como principais descritores disponíveis na base de dados DeCS que foram utilizados, tivemos: Teste de Papanicolaou, Gravidez, Doenças Sexualmente Transmissíveis, Neoplasias e Papillomaviridae - com suas respectivas traduções também como consta na plataforma. Quanto a metodologia dos artigos, foram incorporados tanto materiais de revisão bibliográfica (principalmente para a escrita de tópicos relacionados a visão geral do câncer de colo de útero, do exame e das condições gravídicas) quanto materiais que de fato conduziram um experimento científico (sendo estes aplicáveis principalmente para a discussão do conhecimento de mulheres gestantes acerca do procedimento).

O estudo teve início em abril de 2021 e desde então os artigos foram estudados e resumidos de modo que apenas as informações mais relevantes pudessem ser agregadas como parte do material, suas exposições, sugestões e discussões.

As etapas detalhadas da pesquisa foram: criação de uma pergunta norteadora, estabelecimento dos pontos estruturais que auxiliam no entendimento do tópico, revisão de literatura, compilação de dados obtidos e autoria do estudo.

\section{Resultados e Discussão}

Durante o estudo norteador deste artigo, tornou-se importante a necessidade de elaborar um material claro, informativo e confiável sobre as relações entre HPV, exame de Papanicolau e mulheres grávidas, por diversos fatores: o panorama dos quadros clínicos associados ao vírus a nível nacional, a importância da realização do exame, as informações relacionadas com o período de gravidez que ainda deixam as mulheres hesitantes - destacando as peculiaridades de coleta e de idade gestacional, o que se pode encontrar a nível de citologia - para garantir que a paciente receba um diagnóstico seguro e confiável, esclarecer o melhor curso de tratamento, caso este seja necessário e apresentar a realidade brasileira quando falamos desse contexto em específico - quem são as mulheres que recebem informações adequadas ou não, como é o contexto econômico, social e pessoal em que elas estão inseridas? Como é o seu acesso aos serviços de ginecologia?

Todos esses são elementos centrais de exposição, pesquisa e discussão.

A Organização Mundial da Saúde [OMS], em levantamento conduzido em 2019, como uma parceria com a Agência Internacional de Pesquisa em Câncer (International Agency for Research on Cancer - IARC) informa que a estimativa mundial gira em torno de $80 \%$ das mulheres sexualmente ativas adquirindo HPV ao longo da vida, sendo aqui incluídos todos os tipos. Esses $80 \%$ correspondem a um total aproximado de 290 milhões de mulheres portadoras, sendo que $32 \%$ destas carregam os tipos oncogênicos, estando infectadas pelos tipos 16 ou 18, podendo ocorrer casos onde eles são encontrados simultaneamente.

De acordo com o Instituto Nacional do Câncer [INCA] (2021), o HPV é um problema de saúde pública a nível nacional, especialmente quando discutido o seu perfil oncogênico. Essa informação é corroborada por inúmeras produções científicas e por institutos dedicados ao estudo de virologia ou câncer. O instituto ainda afirma que de colo de útero "é causado pela infecção persistente por alguns tipos de Papilomavírus Humano", sendo importante também levar em conta o estado imunológico da paciente, assim como sua carga viral, os tipos virais presentes e a sua associação aos fatores de risco. As estimativas atualizadas dessa neoplasia giram em torno de 16.590 novos casos anuais, com a proporção de 6.596 deles sendo fatais.

O problema é ainda mais latente se olharmos sob a perspectiva regional. Dentro do norte do país, esse tipo de câncer passa a ser o mais incidente, com valores de $26,24 \%$ a cada 100 mil casos. Os maiores números também persistem quando discutidas as taxas de mortalidade, que localmente são de 12,58 mortes a cada 100 mil pacientes. A realidade específica por região pode ser vista em detalhes na tabela abaixo: 
Tabela 1: Incidência e mortalidade por região Brasileira.

\begin{tabular}{lcccc}
\hline Região & Taxa bruta & Incidência & Casos & Mortalidade \\
\hline Norte & 21,20 & $26,24 / 100 \mathrm{mil}$ & $1.940^{*}$ & $12,58 / 100 \mathrm{mil}$ \\
Nordeste & 17,62 & $16,10 / 100 \mathrm{mil}$ & 5.250 & $6,66 / 100 \mathrm{mil}$ \\
Centro-Oeste & 15,92 & $12,35 / 100 \mathrm{mil}$ & 1.320 & $6,32 / 100 \mathrm{mil}$ \\
Sudeste & 12,01 & $8,61 / 100 \mathrm{mil}$ & 2.680 & $3,71 / 100 \mathrm{mil}$ \\
Sul & 17,48 & $12,60 / 100 \mathrm{mil}$ & 5.400 & $4,99 / 100 \mathrm{mil}$ \\
\hline
\end{tabular}

* Diferença de números pode ser explicada por possível subnotificação, uma vez que a liderança da Região Norte é corroborada por inúmeros levantamentos de dados.

Fonte: Adaptado de INCA, estimativas de 2019 e 2020.

Os números são em sua grande maioria concordantes, estando a única estranheza na quantidade de casos notificados pelo sistema do INCA dentro de nossa região. Isso pode ser discutido levando em consideração as informações disponibilizadas por Silva et al. (2021), que somatizam a relação entre fatores socioeconômicos e acesso facilitado ou não às unidades de atenção básica como contribuintes para que as lesões evoluam e para a maior frequência dos casos de subnotificação. Porém, quando falamos na taxa de mortalidade, a situação problemática dentro da região norte fica evidente, como mostrado na figura 3 - um gráfico dos níveis fatais, divididos de acordo com a localização regional.

Figura 3: Taxas de mortalidade por CCU no Brasil e suas regiões.

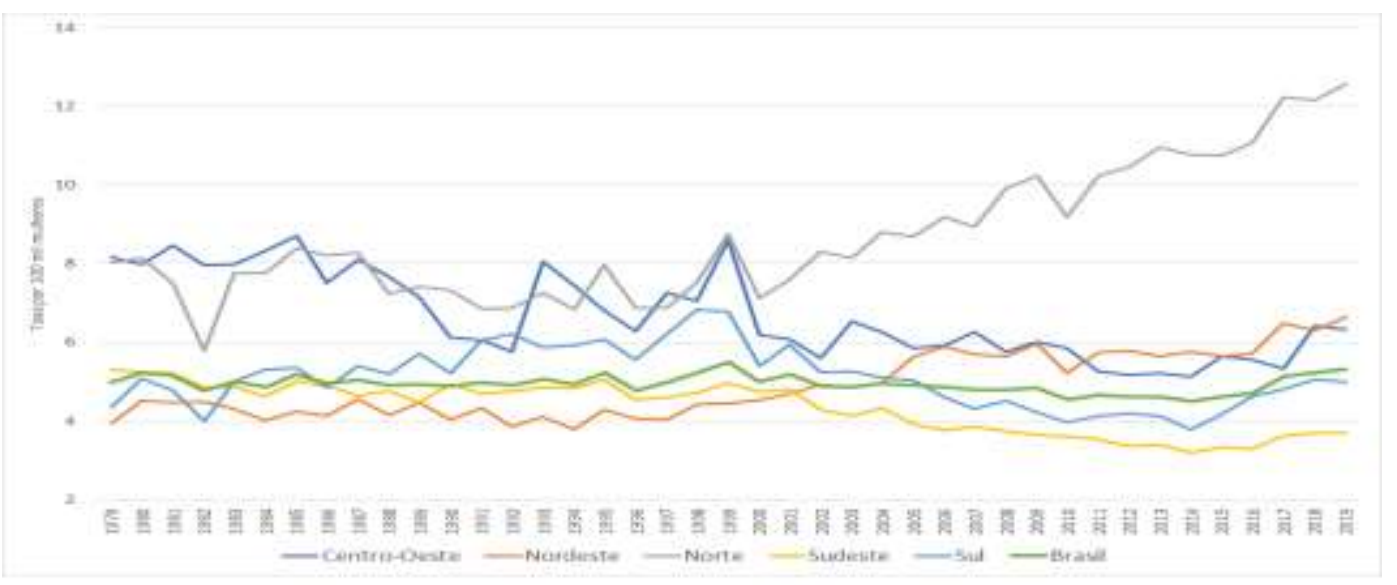

Dentro deste gráfico, é demonstrada a evidência da necessidade especial de atenção, tratamento e rastreamento nas populações femininas nortistas, uma vez que descreve as taxas de mortalidade dentro do intervalo de tempo 1979 - 2019, as quatro últimas décadas. Fonte: INCA (2019).

De acordo com a vivência das autoras, é ainda mais necessário que se tenha atenção para os interiores da região, uma vez que a realidade encontrada nesses locais é ainda mais diferente e grave do que as que se observam em capital. Percebe-se por exemplo, uma falta latente de educação sexual - o que favorece o início precoce e descuidado das atividades - o que também resulta em uma falta de acompanhamento adequado, por dois fatores principais: a ausência de acesso a serviços de saúde (pelo tempo de viagem ou puro desconhecimento) e a escassez de profissionais com preparação adequada.

Quando a paciente consegue acesso aos serviços de fato (por estratégias inclusivas como as ações de saúde que vão até os interiores, dentre as quais podemos citar os hospitais móveis - como os que são navios), ainda existe a preocupação de se combater o senso comum com as informações científicas e que podem ajudar a diagnosticar e resolver o problema. Alguns fatores são essenciais para diminuir a adesão como: fatores pessoais, vergonha, medo, receio de julgamento da comunidade e da reação dos cônjuges.

Segundo o Instituto Brasileiro de Geografia e Estatística [IBGE] (2019), um dos fatores facilitadores da infecção se 
deve ao fato de essa ser uma região com alta incidência de analfabetismo e demograficamente de difícil acesso a locais mais interioranos - assim como o Nordeste, com a segunda maior taxa. Isso se soma outros fatores que propiciam a maior disseminação da infecção, especialmente entre jovens que acabam tendo sua primeira gestação em consequência a não utilização de métodos contraceptivos, ou seu uso errado aliado a multiparidade, fato que também é comentado por Costa \& Ribeiro (2019) quando afirmam que um dos principais fatores de atenção para mulheres adolescentes e jovens, estaria conectado com o início precoce da vida sexual, aliado a ausência de medidas preventivas e a multiplicidade de parceiros sendo todas estas condições já estabelecidas de auxílio para a infecção e manutenção de um quadro por HPV.

Conforme o exposto por Silva et al. (2021) e apoiado por Tanaka et al. (2019) a vacinação é uma ferramenta na prevenção, porém ela em si não é o suficiente para evitar os desconfortos - principalmente os relacionados com: a falta de comunicação em aspectos sexuais entre pais e filhos, o receio na condução de um acompanhamento ginecológico e o desconhecimento em relação a probabilidade de infecção por diferentes subtipos virais - gerados pelo HPV. Além disso, algumas vezes por falta de conhecimento suficiente, as próprias famílias rejeitam a sua aplicação com a ideia que a mesma irá alterar o comportamento sexual de seus filhos.

Ao abordar a realização adequada do procedimento, há um consenso geral na literatura consultada para este projeto sobre o quanto é imprescindível que ele ocorra, e também no que diz respeito a forma de coleta - que, no caso das grávidas, exclui a necessidade de obtenção do material proveniente da endocérvice, devido ao posicionamento da JEC mais exposta, como efeito da ação hormonal. Já quanto ao posicionamento no que diz respeito ao período dentro do qual ele pode ser indicado, divergências foram encontradas: de acordo com a cartilha de atenção básica mais recente do Ministério da Saúde, o exame de Papanicolau pode ser realizado em qualquer período da gestação, devendo inclusive ser requisitado na primeira consulta, para que se consiga observar a citologia do início da gravidez. Esse ponto é corroborado por todos os outros materiais selecionados e analisados, com exceção apenas de Rosa et al. (2018), que em seu artigo ressalta o exame como "complementar, preferencialmente até o sétimo mês de gestação".

Comparando todos os materiais e visando sempre o bem estar da paciente, o INCA (2021) evidencia que a sugestão pode ser a de que o exame seja feito de acordo com as indicações médicas, por ser completamente criterioso e necessário. Também descreve o exame na gravidez como um procedimento respaldado por segurança, não havendo risco de eventos adversos sobre a gestação.

Segundo Troisi e colaboradores (2018), a nível de conforto da gestante, pode-se ressaltar o procedimento dentre o período de meses que corresponde do quarto ao sexto de gestação, principalmente por alguns motivos, como: seus níveis hormonais, que se mostram com alta de progesterona e baixa de estrógeno, durante esse tempo gestacional. Além disso, nesses meses, Sousa et al. (2019), descreve que a mudança de pH esperada para o período gravídico já aconteceu totalmente, permitindo assim uma visualização completa da lâmina, no sentido de aspecto dos grupamentos celulares e quais tipos de condições podem ser encontradas.

Ainda de acordo com este material, essas condições que são específicas desse período são provenientes do modo como as alterações hormonais podem influenciar a microbiota vaginal, podendo aparecer sob diversas formas, dentre elas: epitélio formado por células superficiais, intermediárias, parabasais e basais, de aspecto inicialmente espesso e rico em glicogênio - o que tem relação direta com a população de Lactobacillus spp e o aparecimento de células naviculares.; durante o período gestacional, também se observa a diminuição de células superficiais, sendo esta proporcional a proliferação de intermediárias - o que torna mais propensa a ocorrência de uma mudança de microbiota para que esta favoreça condições inflamatórias, em sua maioria causadas em conjunto com alterações de pH e resultando em corrimentos por cocos, bacilos, e Lactobacillus spp.

Além destes, é possível que se observem quadros de vaginite e vaginose, em sua grande maioria causados por 
Gardnerella vaginalis ou mais um diferente, o de candidíase vulvo vaginal (CVV), por Candida spp, também recebe destaque o quadro de tricomoníase, pelo agente Trichomonas vaginallis.

Como explicação sugerida, podemos chamar atenção para o fato de que existe uma falha na informação adequada atingindo a mulher, no que diz respeito a sua higiene íntima. Muitas das vezes as pacientes não se atentam em como fazer isso corretamente, o que favorece o desequilíbrio da própria microbiota vaginal, a alteração de $\mathrm{pH}$ e a possibilidade de infecções coexistentes - rotinas observadas pelas autoras deste estudo, mostram a existência de mulheres com amostras que tenham mais de um microrganismo.

Sendo assim, é importante manter o acompanhamento citológico durante esse período, uma vez que essas infecções são favorecidas durante os meses de gravidez e precisam de atenção adequada.

Como também detalhado por Freitas et al. (2020) e Ferreira et al. (2020) esses patógenos (os mais frequentes estando representados na Figura 4) podem vir a ocasionar partos prematuros e até óbito do feto, deixando evidente a necessidade da realização do exame durante as consultas do pré-natal.

Figura 4: Candida spp., Trichomonas vaginallis e Gardnerella vaginallis em esfregaço.

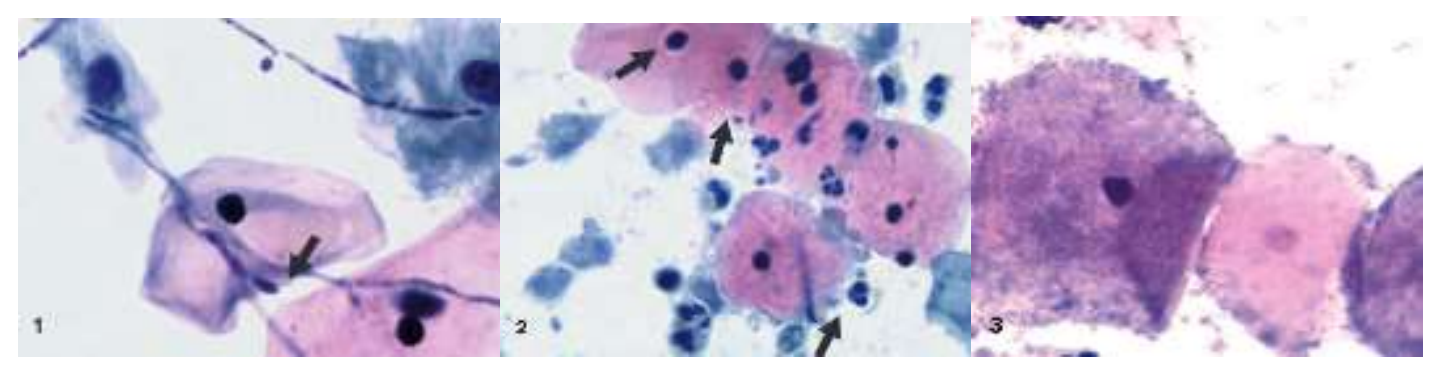

Fonte: Adaptada de Caderno Referência 1: Citopatologia Ginecológica, 2012.

Partindo de um princípio de pensamento apoiado por Tanaka et al. (2019) e Teixeira et al. (2019), uma vez que se conhece a importância da citologia e todas as possibilidades diagnósticas de uma gravidez (não podendo ser excluída também a checagem de um epitélio normal, aonde se observariam tipos celulares presentes e níveis hormonais adequados), se torna essencial que essa informação seja capaz de atingir a mãe e mulher que pode vir a necessitar de rastreamento de rotina ou tratamento mediante diagnóstico. Mas muitas das vezes esse processo se torna difícil por fatores como vergonha, incômodo, falta ou erro de informações - principalmente no que diz respeito a crença de que o exame é doloroso ou que vai prejudicar o feto durante o período gestacional, o que acaba gerando uma adesão inferior a desejada.

Concordando com este tipo de análise, artigos como o de Silva et al. (2018) deram atenção especial a esses fatores que podem ser limitantes a nível pessoal para a realização do exame, mostrando que as razões levam em conta múltiplos fatores, como por exemplo: escolaridade, faixa etária, estado civil, renda e sentimentos pessoais - frequentemente de desconforto, medo ou vergonha. Além disso, as explicações sobre a serventia do exame e os seus benefícios eram frequentemente incompletas.

Conforme o exposto pela tríade de estudos conduzidos por Tanaka et al. (2019); Rosa et al. (2018) e Teixeira et al. (2019) a grande maioria das grávidas estudadas que estava realizando o exame pela primeira vez, era o grupo de adolescentes e mulheres jovens, em geral dentro de uma média correspondente à faixa de 16 a 24 anos, com idade de início da vida sexual em torno de 14 até os 19.

Essa faixa de idade, pelo que afirmam Sousa e colaboradores (2018) e Bober (2019) expõe a mulher a um maior risco de infecção, por somar o acontecimento da coitarca com o posicionamento anatômico da JEC no trato genital. Sendo assim, é uma realidade importante de se observar a garantia aos cuidados de educação sexual e ginecológicos, uma vez que o período 
gravídico pode ser o contato inicial de uma mulher com essas realidades.

É viável, como reforçado por Gasparin et al. (2020), assim como por Ribeiro \& Costa (2019) que uma das soluções encontradas para este cenário, seja a de voltar atenções especiais para as políticas de educação sexual dentro da atenção primária e básica a saúde, principalmente com preparo adequado do profissional para que esse panorama de anos possa mudar positivamente. O que é completo pelo ponto de vista de Silva et al. (2021) que também destaca a importância da educação sexual nas escolas. Essas medidas podem funcionar modo a informar e incluir cada vez mais mulheres em políticas que possibilitem o cuidado e rastreamento adequados - e que, em um contexto específico e a longo prazo, pode trazer uma crescente qualidade de vida às gestantes brasileiras.

\section{Conclusão}

Após a condução deste estudo é possível perceber alguns pontos principais: primeiramente o de que embora os estudos utilizados demonstrem uma base confiável na execução do exame de Papanicolau em gestantes, onde este procedimento não trará nenhum mal ao feto se for realizado no período adequado e por um profissional capacitado, é observada também a negação das gestantes na realização por medo de complicações ou pelo desconhecimento do exame neste período. Apesar dos benefícios que o exame pode proporcionar em relação a saúde do feto e da mãe, constatou-se que um dos pontos cruciais está relacionado com a educação sexual, que poderia ser efetivamente aplicada nas escolas, dado que em maioria as mulheres com conhecimento insatisfatório são jovens, periféricas e de nível social econômico baixo.

Um dos pontos críticos foi perceber que apesar do passar dos anos, o panorama ainda se mantém essencialmente o mesmo - com a falta de assistência e educação adequadas, a não adesão aos serviços de saúde e o estabelecimento do câncer como um problema de saúde pública cada vez mais preocupante - o que leva a interligar todos os fatores expostos no presente trabalho, em vista disso sugerindo a necessidade de ações mais eficazes, a continuidade na linha de pesquisa, a facilitação do acesso a conteúdo cientifico que seja esclarecedor, e a capacitação profissional contínua, para a orientação e execução dos exames dentro da saúde da mulher - no caso do artigo, em específico gestantes - e atenção devida a intervenções nos interiores mais afastados da Região Norte do Brasil, já que suas notificações tendem a ser incompletas por fatores como deslocamento. Trata-se de uma estratégia efetiva, que para ser melhorada precisa apenas de esforços conjuntos.

Parte desses esforços conjuntos é a necessidade de incluir uma linha de pesquisa continuada em torno do tema, especialmente com informações no que diz respeito aos dados locais de adesão específica das gestantes ao papanicolau conectando estes achados com os quantitativos de caso de CCU no Brasil, percebendo se eles apresentam melhora, se mantém estáveis ou pioram; além de ser interessante também explorar o aspectos da infecção não oncogênica por HPV em gestantes descrevendo principalmente se há algum tipo de consequência para a mãe ou o feto; com esta linha de raciocínio também podendo sugerir um estudo centrado na resposta imunológica ao HPV durante o período gestacional - qual o perfil de resposta, sobretudo destacando as modulações, alterações e limitações possíveis de se ocorrer.

Com este tipo de abordagem que leve em conta a preparação profissional adequada e a divulgação progressiva de conhecimento científico por meio de estudos, espera-se que a realidade no que diz respeito ao câncer de colo de útero possa, finalmente, começar a mudar para melhor.

\section{Referências}

Agarwal, R. (2019). Colposcopic changes in the cervix during normal pregnancy and puerperium. International Journal of Clinical Obstetrics and Gynecology, 3(6), 163-168.

Biblioteca Virtual em Saúde: Ministério da Saúde. (2011). Exame preventivo do câncer de colo uterino papanicolau. https://bvsms.saude.gov.br/bvs/dicas/237_papanicolau.html. 
Bober, L., Guzowski G., Mokzulska H. \& Sieroszewski P. (2019). Influence of human papilloma virus (HPV) infection on early pregnancy. Ginekologia polska, 90(2), 72-75.

Brasil. (2012). Ministério da Saúde. Caderno de referência 1: citopatologia ginecologica. https://bvsms.saude.gov.br/bvs/publicaco es/tecnico_citopatologia_caderno_referencia_1.pdf.

Brasil. (2013). Ministério da Saúde. Cadernos de atenção básica - atenção ao pré-natal de baixo risco. https://edisciplinas.usp.br/pluginfile.p hp/5256763/mod_resource/content/1/Cadernos\%20A\%20B\%C3\%A1sica_32_pr\%C3\%A9\%20natal.pdf.

Brasil. (2016). Ministério da Saúde e INCA. Diretrizes brasileiras para o rastreamento do câncer de colo de útero. Acesso em 06 de junho de 2021. Disponível em: https://www.inca.gov.br/sites/ufu.sti.inca.local/files//media/document//diretrizesparaorastreamentodocancerdocolodoutero_2016_corrigido.pdf.

Brasil. (2017). Prefeitura de Goiânia. Pop no 11: coleta de material para exame citopatlógico de colo uterino. https://www.saude.goiania.go.gov.br/wpuploads/sites/3/2020/12/POP_11_COLETA_MATERIAL_CITOPATOLOGICO.pdf.

Brasil. (2020). INCA. Estimativa 2020 | incidência de câncer no brasil. https://www.inca.gov.br/sites/ufu.sti.inca.local/files//media/document//estimativa2020-incidencia-de-cancer-no-brasil.pdf.

Casarin S. T., Porto A. R., Gabatz R. I. B., Bonow C. A., Ribeiro J. P. \& Mota M. S. (2020). Tipos de revisão de literatura: considerações das editoras do Journal Of Nursing And Health. Journal Of Nursing And Health, 10(5), 1-7.

Cirino, E. S., \& Barbosa, M. C. L. (2020). Incidência do Papiloma Vírus Humano-HPV em gestantes: uma revisão integrativa. Brazilian Journal of Health Review, 3(3), 6727-6736.

Conselho nacional de saúde. (2020). Semana da saúde. http://conselho.saude.gov.br/ultimas-noticias-cns/1057-semana-da-saude-2020-cns-propoe-queconselhos-intensifiquem-acoes-online-contra-o-desmonte-do- sus.

Costa, A. É. L., da \& Souza, J. R. (2018). Implicações psicossociais relacionadas à assistência à gestante com câncer: percepções da equipe de saúde. Revista da $\operatorname{SBPH}, 21(2), 100-122$.

Costa, D. A. V., \& Ribeiro, T. R. (2019). Vulnerabilidade de jovens e adolescentes à infecção por HPV e as condutas preventivas da enfermagem. Temas em Educação e Saúde, 15(2), 217-233.

Da Silva, L. K. V., Vieira, A, Villar L., Morais, K., Batista I. \& Luvizotto J. (2018). Alteração hormonal no período reprodutivo. Pró-Reitora de PósGraduação, Pesquisa e Extensão, Curitiba, PR, Brasil, 24.

Dos Santos, O., Renata, F., \& Fernandes, L. C. S. (2019). A importância do enfermeiro na conscientização e prevenção do HPV. Psicologia e Saúde em debate, 5(1), 80-109.

Ethirajan, S., Srinidhi, R. \& Jayashree, K. (2018). Pap smear in antepartum women: an opportunity to screen and create awareness. International Journal of Reproduction, Contraception, Obstetrics and Gynecology, 7(10), 4093-4096.

Ferreira, E. V. F., Santos M., Oliveira K. \& Carvalho J. (2020). Vaginose bacteriana: fator de risco no parto prematuro. Cadernos da Medicina-UNIFESO, 2(3), 80-85

Freitas, L. F. Q, Maia L., Deus M., Oliveira S. \& Peres A. (2020). Prevalência de microrganismos em secreção vaginal de gestantes de alto risco de uma maternidade em Caruaru, Pernambuco, Brasil. Jornal Brasileiro de Patologia e Medicina Laboratorial, 56, 1-6.

Gasparin, V. A., Schmalfuss, J. M., Zanotelli, S. S., \& Silva, E. F. (2020). Rastreamento do câncer de colo do útero durante o acompanhamento pré-natal. Revista Eletrônica de Enfermagem, v. 22(63482), 1-8.

Guimarães, T. de S. F., Sousa V. L. O. \& Guimarães, T. M. M. (2020). Exame citopatológico do colo do útero em gestantes: uma revisão integrativa. Research, Society and Development, 9(7), 1-16.

INCA. (2021). Controle do câncer de colo de útero: conceito e magnitude. https://www.inca.gov.br/controle-do-cancer-do-colo-do-utero/conceito-emagnitude.

INCA. (2021). Detecção precoce. https://www.inca.gov.br/en/node/1194.

INCA. 2021. Perguntas Frequentes: HPV. https://www.inca.gov.br/perguntas-frequentes/hpv.

Instituto Brasileiro de Geografia e Estatística IBGE. (2019). Pesquisa nacional por amostra de domicilio continua. https://biblioteca.ibge.gov.br/visuali zacao/livros/liv101736_informativo.pdf.

Leite, K. N. S., Silva, J. P., Sousa K. M, Rodrigues S. C., Souza T. A., Alves J. P., Souza A. R. D. \& Rodrigues, A. R. S. (2018). Exame Papanicolau: fatores que influenciam a não realização do exame em mulheres de 40 a 65 anos. Arquivos de Ciências da Saúde, 25(2), 15-19.

Lélis, B. D. B., Dusso, M. I. S, Souza, F. L. P., \& Bernardes, N. B. (2019). Tratamento do Câncer de Colo do Útero em Gestantes. ID on line Revista de psicologia, 13(45), 433-438.

Maia, R. C. B., Silveira, B. L., \& De Carvalho, M. F. A. (2018). Câncer do colo do útero: papel do enfermeiro na estratégia e saúde da família. Revista Científica da Faculdade de Educação e Meio Ambiente, 9(1), 348-372.

Ministério da saúde; INCA. (2021). Detecção precoce do câncer. Disponível em: https://www.inca.gov.br/publicacoes/livros/deteccao-precoce-do-cancer.

Organização Mundial da Saúde (2002). OMS. Cervical cancer screening in developing countries. https://www.who.int/cance r/media/en/cancer_c ervical_37321.pdf. 
Research, Society and Development, v. 10, n. 11, e500101120015, 2021

(CC BY 4.0) | ISSN 2525-3409 | DOI: http://dx.doi.org/10.33448/rsd-v10i11.20015

Priya, S. Senthil \& Shankar, R. (2018). PAP smear in pregnancy: a hospital-based study. (2018). International Journal of Reproduction, Contraception, Obstetrics and Gynecology, 7(12), 4924-4928.

Rodrigues R. A. R., Silva, T. S. L., Carvalho, I. C. S., Sousa A. S. J.; Rodrigues A. B., \& Penha J. C. (2018). Exame citopatológico do colo do útero: investigação sobre o conhecimento, atitude e prática de gestantes. Cogitare Enfermagem, 23(2), e52589.

Silva Mayara, D. T., Marques Renata, B., \& Costa, Leandro, O. (2021). Câncer de colo de útero: barreiras preventivas no século 21. Brazilian Journal of Health Review, 4(2), 7610-7626.

Sousa A. P., Medeiros, D. B., Cordeiro, L. V., Muniz, V. M., \& Filho, A. A. O. (2019). Alterações da microbiota vaginal na gestação e seu significado clínico: revisão de literatura. Journal of Medicine and Health Promotion, 4(4), 1254-1266.

Sousa G. P; Von Ledenburg E. I. C. F., Araújo, M. V. A., Dias G. A. S., Chagas E. P. F., Quaresma J. A. S. \& Fuzii H. T. (2018). Aspectos clínicos e epidemiológicos da infecção genital pelo papilomavírus humano em gestantes do município de Imperatriz, estado do Maranhão, Brasil. Revista PanAmazônica de Saúde, 9(3), 31-38.

Tanaka, E. Z., Kamizaki S. S., Quintana S. M., Pacagnella R. C. \& Surita F. G. (2019). Conhecimento de adolescentes gestantes sobre o papilomavírus humano. Revista Brasileira de Ginecologia e Obstetrícia, 41(5), 291-297.

Teixeira, L. de M., Santos A. A. P., Sanches M. E. T. L., Silva J. M. O. \& Cavalcante M. V. (2019). Exame preventivo para o câncer de colo durante a gravidez: experiências das gestantes. Rev. baiana enferm, e33698-e33698.

Terlan, R. J., \& Cesar, J. A. (2018). Não realização de citopatológico de colo uterino entre gestantes no extremo sul do Brasil: prevalência e fatores associados. Ciência \& Saúde Coletiva, 23(11), 3557-3566.

Troisi R., Bjørge T., Gissler M., Grotmol T., Kitahara C. M., Myrtveit sæther S. M., Ording A. G., Sk€old C., Sørensen H. T., Trabert B. \& Glimelius I. (2018). The role of pregnancy, perinatal factors and hormones in maternal cancer risk: a review of the evidence. Journal of Internal Medicine, 283(5), 430445.

World Health Organization \& International Agency for Research on Cancer. (2019). Human papillomavirus and related diseases report Brazil. https://hpvcentre.net/statistics/reports/BRA.pdf?t=1625848596624. 